\title{
Peertechz
}

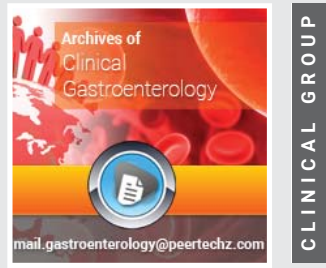

\section{Carcinoma cuniculatum of the esophagus-diagnostic and treatment dilemma}

\section{Matheus Falasa ${ }^{1}$, Alexander Ayzengart ${ }^{1}$, Michael Walters ${ }^{1}$, Xiuli Liu ${ }^{2}$ and Olusola Oduntan ${ }^{1 *}$}

${ }^{1}$ Department of Surgery, University of Florida, Gainesville FL, USA

${ }^{2}$ Department of Pathology, University of Florida, Gainesville FL, USA

Received: 24 June, 2020

Accepted: 12 August, 2020

Published: 13 August, 2020

${ }^{*}$ Corresponding author: Olusola Oduntan, MD,FACS Department of Surgery, University of Florida, 1600 SW Archer Road, Gainesville, FL 32610, USA, Tel: 352-2735506; Fax: 352-273-5513; E-mail: solaodunt@aol.com ORCID: https://orcid.org/0000-0001-8708-1701 https://www.peertechz.com

\section{Check for updates}

\section{Abstract}

Carcinoma cuniculatum is a rare variant of well-differentiated squamous cell carcinoma of the esophagus, with fewer than twenty cases reported in the literature [1]. Diagnosis is often delayed due to failure of endoscopic biopsies to yield a definitive tissue diagnosis. We present the case of a patient with carcinoma cuniculatum of the esophagus who was misdiagnosed as achalasia, and consequently did not undergo surgical resection of the malignancy for nine months.

\section{Introduction}

Carcinoma cuniculatum is frequently diagnosed from oral and skin lesions, particularly of the plantar aspect of the foot. Esophageal carcinoma cuniculatum was first reported in the literature in 2005. Pathology is characterized by burrowing channels of extremely well-differentiated squamous epithelium [2]. The etiology of this lesion is unknown, with previous studies unable to demonstrate any association with human papilloma virus (HPV), although there is some association with smoking $[2,3]$.

A semi-quantitative histologic scoring system was developed by Chen et al, assigning points for: hyperkeratosis, acanthosis, dyskeratosis, deep keratinization, intraepithelial neutrophils, neutrophilic micro-abscess, focal cytologic atypia, koilocyte-like cells, and keratin-filled cysts or burrows [4] (Figure 1). This improves diagnostic sensitivity in biopsies otherwise read as benign, but the diagnosis of carcinoma cuniculatum still remains challenging.

Here we report the case of a young female with dysphagia due to carcinoma cuniculatum of the esophagus who underwent surgical resection nine months after initial presentation, due to failure to establish a definitive diagnosis on preoperative biopsy specimens.

\section{Case report}

The patient was a 37 year old female with a history of tobacco abuse, who had presented to an outside hospital with dysphagia, food regurgitation, and weight loss of up to $50 \mathrm{lbs}$ over 6 months.

Computerized tomographic scan (CT scan) of chest and abdomen with oral contrast showed a "homogeneous soft tissue thickening at the gastroesophageal (GE) junction" with failure of contrast to advance into the stomach (Figure 2).

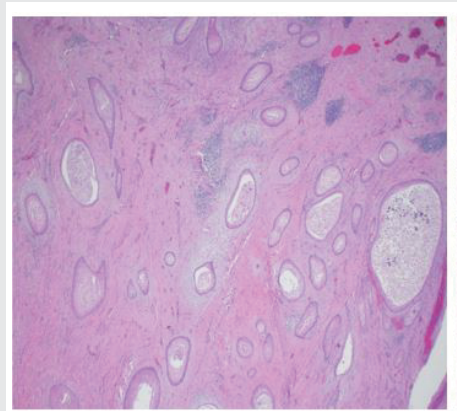

A

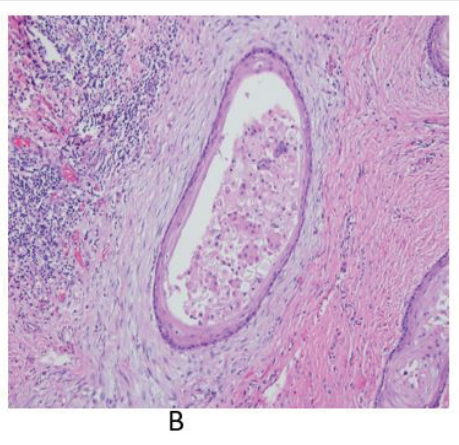

B
Figure 1: (A) \& (B): show an infiltrating carcinoma consisting of many cysts lined by bland squamous epithelium in the muscularis propria, adventitial and subserosal tissue.

Citation: Falasa M, Ayzengart A, Walters M, Liu X, Oduntan O (2020) Carcinoma cuniculatum of the esophagus-diagnostic and treatment dilemma. Arch Clin Gastroenterol 6(2): 057-059. DOI: https://dx.doi.org/10.17352/2455-2283.000080 
She underwent Esophagogastroduodenoscopy (EGD) by gastroenterologist and was diagnosed with "findings suggestive of achalasia". Balloon dilatation, as well as Savary dilation of the esophagus were initially carried out but her symptoms were not relieved. She was then referred to a surgeon for laparoscopic Heller myotomy. Intra-operative endoscopy revealed an esophageal mass at $33 \mathrm{~cm}$ from the incisors with intact overlying mucosa. The mass extended across the GE junction onto the stomach, and it was difficult to advance the endoscope past the GE junction. Dissection to carry out a Heller myotomy was tedious, so the procedure was aborted and a gastrotomy was created to inspect the mass which was observed to be submucosal in location, and a "full-thickness biopsy" was performed. Feeding gastrostomy tube was placed, and wedge resection of the stomach was performed to close the gastrotomy site.

Histology of biopsy specimens taken from stomach, esophagus, GE junction, and surrounding lymph nodes were non-diagnostic, reported as showing: "features of chronic inflammation, absence of dysplasia, metaplasia or cellular atypia".

Nine months after this, she was referred to our out-patient esophageal surgery clinic for evaluation for esophagectomy. Imaging studies and preoperative endoscopic evaluation were scheduled, but prior to her appointment date, she presented to the emergency department with acute onset of severe upper abdominal pain. Plain chest radiograph (CXR) and CT scan of abdomen showed large-volume intra-peritoneal free air concerning for perforated gastric fundus (Figure 3). There was no pleural effusion or extravasation of enteric contrast material.

After fluid resuscitation and initiation of intravenous antibiotics and antifungal therapy, she was taken to the operating room urgently for exploratory laparotomy. Findings included a palpable firm mass just distal to the GE junction, and a gastric fundus perforation adjacent to an old staple line. Intraoperative endoscopy confirmed a narrowing above the GE junction with an intact mucosa. The area of gastric perforation was resected and primarily repaired in two layers.

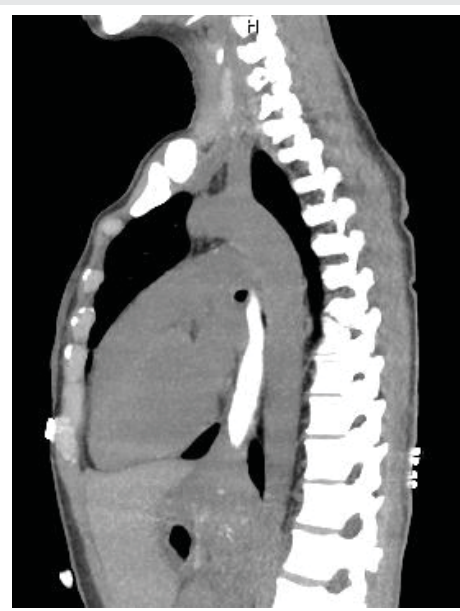

Figure 2: Computerized Tomographic (CT) Esophagram showing failure of passage of contrast beyond the gastroesophageal (GE) junction.

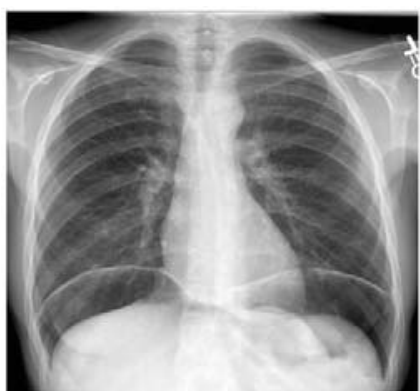

Figure 3A

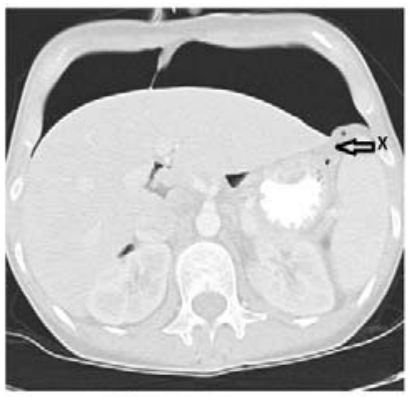

Figure 3B
Figure 3: (A) Plain chest radiograph showing free air under right and left hemidiaphragm. (B): CT scan of abdomen demonstrates large pneumoperitoneum with black $\mathbf{X}$ showing air escape from gastric fundus.

Pathology from the submitted specimens was reported as benign.

Postoperatively, visceral angiography was performed to evaluate the gastric blood supply, and it was reported as showing normal vascular pattern.

After recovering from her emergency laparotomy, she was returned to the operating room a few days later for attempt at definitive management.

The laparotomy was re-opened and the abdomen was reexplored. The distal esophageal mass across the GE junction was felt to be intramural, firm to palpation, and consequently suspected to be a benign lesion, such as leiomyoma. Enucleation of the mass was attempted by first opening the adventitial layer and then dissecting the muscle layers. Frozen section of portions of the mass was initially reported as "normal smooth muscle". Because it was difficult to completely separate the mass from the esophageal submucosa, decision was made to perform an Ivor Lewis esophagectomy.

However, evaluation of the stomach showed presence of suspicious areas of thickening around the areas of perforation repair in the fundus and gastric body, in addition to evidence of compromise to the gastro-epiploic arterial arcade from previous operations. It was then decided that the stomach would not be a suitable conduit for esophageal replacement after Ivor Lewis esophagectomy.

Subtotal gastrectomy with distal esophageal resection was carried out, with reconstruction via a Roux-en-Y esophagojejunostomy. A feeding jejunostomy tube was also placed for enteral nutrition supplementation.

The patient had an unremarkable recovery and she was discharged home after a short stay.

Surgical pathology report showed: "Invasive, extremely well differentiated squamous cell carcinoma (carcinoma cuniculatum) of the gastroesophageal junction, measuring 5 $\mathrm{cm}$ in greatest dimension. The tumor invades the adventitia with small perforation. Proximal and distal margins are free of carcinoma. Radial / adventitial margin of the esophageal portion is focally positive for carcinoma. Lymphovascular invasion is not identified. Four lymph nodes are negative for carcinoma. AJCC Pathologic Stage ( ${ }^{\text {th }}$ edition): pT3 No Mx". 
The final pathology on the gastric (perforation) resection showed: "Invasive extremely well differentiated squamous cell carcinoma (carcinoma cuniculatum) involving gastric muscularis propria". It is of note that the frozen section sent during the gastric resection operation was reported as: "bland squamous epithelium-lined cysts with chronic inflammation and benign squamous mucosa"

This case was presented at our multidisciplinary tumor board. Given the pathologic stage of pT3NoMx, consensus was reached that the patient should receive adjuvant systemic chemotherapy. She would have been considered for preoperative neoadjuvant therapy if a tissue diagnosis of cancer was made on biopsy and the stage was $\mathrm{T} 2$ or greater on endoscopic ultrasound.

She has been tolerating oral nutrition, gaining weight, and has returned to work.

\section{Comment}

Squamous cell carcinoma of the esophagus typically manifests as an invasive lesion with ulceration of the mucosa overlying the tumor, hence tissue biopsy is expected to yield a diagnosis with a high degree of certainty. Carcinoma cuniculatum (extremely well differentiated squamous cell carcinoma) of the esophagus, on the other hand, is morphologically an intramural tumor with an intact and smooth overlying mucosa, with difficulties encountered obtaining representative tissue for preoperative diagnosis.

Esophageal resection of the Ivor Lewis type is sufficient operative approach for this patient, but the finding of tumor in the gastric perforation specimen and the compromised gastric blood supply necessitated the use of jejunum as an alternate conduit for restoration of alimentary continuity.

If a definitive diagnosis had been achieved on biopsy, and subsequent endoscopic ultrasound (EUS) performed for staging, this patient would have benefitted from the use of neoadjuvant chemotherapy and radiotherapy prior to resection of her esophageal cancer. This factor guided the decision made to refer her for adjuvant chemotherapy after recovery from esophagectomy. Irradiation of the jejunal conduit was not considered prudent, hence its omission from the adjuvant treatment plan.

Unlike squamous cell carcinoma of the esophagus, studies on carcinoma cuniculatum of the esophagus have reported good long-term survival after esophagectomy, including cases with tumor invading the adventitia, with most deaths occurring in the early postoperative period secondary to surgical complications [3]. Carcinoma cuniculatum of the esophagus is not believed to have metastatic potential [5]

The rarity of carcinoma cuniculatum makes preoperative diagnosis difficult. In this case, a delay in diagnosis led to the delay in referral of the patient to the appropriate specialist for initiation of appropriate definitive surgical therapy.

\section{References}

1. Dick TM, Hag ME, Mallery SJ, Amin K (2018) Esophageal Carcinoma Cuniculatum Associated with Non-Necrotizing Granulomatous Inflammation and Lymphadenopathy. Am J Case Rep 19: 790-795. Link: https://bit.ly/31IL2En

2. De Petris G, Lewin M, Shoj T (2005) Carcinoma Cuniculatum of the Esophagus. Ann Diagn Pathol 9: 134-138. Link: https://bit.ly/30LA2qy

3. Landau M, Goldblum JR, DeRoche T, Dumot J, Downs-Kelly E, et al. (2012) Esophageal carcinoma cuniculatum: Report of 9 cases. Am J Surg Pathol 36: 8-17. Link: https://bit.ly/3gOVh0v

4. Chen D, Goldblum JR, Landau M, Rice TW, Pai RK (2013) Semiquantitative Histologic Evaluation improves Diagnosis of Esophageal Carcinoma Cunuculatum on biopsy. Modern Pathology 26: 806-815.

5. Koch LK, Templeton A, Westerhoff M (2018) Carcinoma Cuniculatum: A Rare Cause of a gastroesophageal Junction Mass. Clin Gastroenterol Hepatol 16: xxxvii-xxxviii. Link: https://bit.ly/3kDMsZJ
Discover a bigger Impact and Visibility of your article publication with

\section{Peertechz Publications}

\section{Highlights}

* Signatory publisher of ORCID

* Signatory Publisher of DORA (San Francisco Declaration on Research Assessment)

* Articles archived in worlds' renowned service providers such as Portico, CNKI, AGRIS, TDNet, Base (Bielefeld University Library), CrossRef, Scilit, J-Gate etc.

* Journals indexed in ICMJE, SHERPA/ROMEO, Google Scholar etc.

* OAI-PMH (Open Archives Initiative Protocol for Metadata Harvesting)

* Dedicated Editorial Board for every journal

* Accurate and rapid peer-review process

* Increased citations of published articles through promotions

- Reduced timeline for article publication

Submit your articles and experience a new surge in publication services (https://www.peertechz.com/submission).

Peertechz journals wishes everlasting success in your every endeavours.

Copyright: @ 2020 Falasa M, et al. This is an open-access article distributed under the terms of the Creative Commons Attribution License, which permits unrestricted use distribution, and r eproduction in any medium, provided the original author and source are credited. 